\title{
Apresentação
}

\section{Dinâmicas territoriais e desenvolvimento sustentável}

IVALDO GEHLEN* E ALBERTO RIELLA**

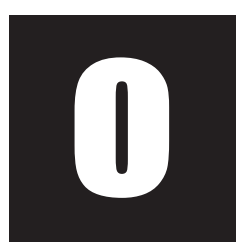

atual debate sobre o território configura uma amálgama de visões que oscilam entre percebê-lo como uma configuração estática, até a visão de território como realidade complexa e dinâmica, em permanente transformação, reflexo das dinâmicas físicas, socioeconômicas e culturais do contexto local.

A noção de território apresenta controvérsias porque amplifica nosso olhar e diversifica as possibilidades de compreender, sistematizar e modificar a realidade complexa. O território é uma referência globalizante, algo que está sendo construído em paralelo ao conceito de globalização, opondo-se por vezes a este pelas possibilidades que oferece de reconhecer e valorizar as especificidades locais e regionais no enfrentamento à pretensão uniforme da idéia de globalização. Outras vezes a idéia de território oferece chances de inclusão do particular no global, pelas oportunidades de desenvolvimento de potencialidades locais e regionais que as valorizam e lhes dão visibilidade.

O território constituído como espaço social produzido e delimitado por um entorno que o ordena é construído como representação: como tal, pode ser uma ferramenta, um recurso do desenvolvimento econômico e

* Professor do Departamento de Sociologia e dos Programas de Pós-Graduação de Sociologia, de Desenvolvimento Rural e de Agronegócios da UFRGS. Endereço eletrônico: ivaldo@vortex.ufrgs.br

** Professor do Departamento de Sociologia - Universidad de la República (Uruguai), Doutor em Sociologia - UFRGS, coordenador geral da Rede de Desenvolvimento Territorial e Integração Regional (ReDeTIR). 
social. Nesta perspectiva se incluem no processo do planejamento as diferentes dimensões do território destacando sua complexidade. Todo o conjunto é afetado; ao mesmo tempo, apontam-se especificidades e particularidades internas às delimitações da sociedade global, as quais interagem nos processos de construção identitárias sócio-econômico-culturais que atribuem sentido ao local. O olhar holístico aponta para a incorporação de recursos específicos, propicia a invenção de alternativas de competitividade dos produtos gerados no interior de um território, vantagem compartida coletivamente.

Colocam-se desafios para a ação coletiva no sentido de gerir a apropriação compartilhada dos benefícios desta competitividade; tais desafios podem ser encaminhados através da negociação dos conflitos, de regras claras e comuns, da tomada de decisões coletivas. Este processo constrói um patrimônio sociocultural respaldado na tradição (história local) e possibilita apontar alternativas inovadoras. Aos poucos, sedimenta uma memória coletiva rearticulando os saberes e as relações com o meio natural e com o patrimônio material e simbólico e desencadeando processos de construção de cidadania. Seria inimaginável, nesse processo compartilhado, a implementação de um modelo de desenvolvimento que não seja sustentável segundo os padrões atuais do conhecimento e das tecnologias.

A abordagem da realidade sob o enfoque de território leva a repensar a dicotomia elaborada, na modernidade, entre rural e urbano e suas respectivas funções. A agregação de novos valores, não necessariamente econômicos, às atividades agropecuárias - como, por exemplo, a qualidade nutritiva e a sanidade dos alimentos - se soma à preservação ambiental e ao desenvolvimento cultural das tradições, das identidades e de novas organizações societárias. A questão da competitividade adquire novos significados e traz novos valores, inclusive simbólicos. Outras atividades no território encontram coerência em escala local e regional, como agroecoturismo, artesanatos, agroindústrias "caseiras", valores estéticos ambientais. Nesta 
perspectiva, a problemática da nova ruralidadade situa-se como construção de uma distinta funcionalidade do rural e, portanto, repõe as interações societárias no espaço.

O conceito de território inclui a noção de patrimônio sociocultural, e a necessidade de mobilização dos recursos e das competências através de atribuições de responsabilidades sociais, por meio de processos participativos. A mobilização do patrimônio local induz à redinamização do território, através de novas modalidades de integração e de valorização dos recursos e dos produtos locais, como componentes do patrimônio sociocultural coletivo. Não se trata simplesmente de integrar de forma positiva os conhecimentos científicos e técnicos nos sistemas cognitivos e de agir de forma solidária, mas de estabelecer relação de cooperação e negociação do conflito para que as normas e os códigos de conduta sejam subjetivados no sistema de representações para que constituam parte da identidade social.

Os artigos do dossiê desta edição da revista Sociologias analisam as dinâmicas territoriais e o desenvolvimento sustentável na perspectiva da territorialidade, através da qual se pode analisar os processos de desenvolvimento, com suas complexidades, universalidades e particularidades. $\mathrm{O}$ dossiê Sociedade e Território é resultado de uma rede de pesquisadores, construída para compartilhar leituras e significados dessas dinâmicas.

A rede Integração Regional e Desenvolvimento Territorial: uma perspectiva comparada e de cooperação entre a Bacia do Prata no MERCOSUL e o Sul da Europa na União Européia ${ }^{1}$ está se estruturando a partir do Programa da UE ALFA (América Latina Formação Acadêmica), articula pesquisadores de oito Universidades, ${ }^{2}$ difunde estudos sobre a temática e promove a formação de doutores que desenvolvem teses sobre o tema da rede. As regiões selecionadas do Mercosul (Argentina, Sul do Brasil e Uruguai) e do Sul da

1 Página da rede na internet: http://redetir.tripod.com

2 Constituem a Rede as seguintes universidades através de seus Programas ou Departamentos de Sociologia: Universidade Federal do Rio Grande do Sul (Brasil); Universidad Nacional del Comahue, Universidad Nacional del Litoral (Argentina); Universidad de la República (Uruguai); Universidad de Granada, Universiad de Múrcia (Espanha); Universidade Técnica de Lisboa (Portugal); Université de Toulouse II-Le Mirail (França). 
Europa (Sul da França, Espanha e Portugal) para o ALFA, possuem índices de urbanização relativamente altos, estão interligadas internamente por uma rede densa de cidades de vários portes e por uma agricultura empresarial produtivista fortemente vinculada aos complexos agroalimentícios. A agricultura familiar, e de maneira geral a economia com base na empresa familiar, ocupa destaque nestes territórios, ensejando a expectativa de sustentabilidade através de dinâmicas comuns.

Os intercâmbios entre União Européia e MERCOSUL se incrementaram de tal modo que ela se converteu no principal sócio comercial deste território associado (MERCOSUL). As negociações de acordos de livre comércio entre União Européia, o MERCOSUL, o Tratado de Livre-Comércio de América do Norte e outros países da área, permitem antecipar um incremento desta tendência nos próximos anos. Este incremento e diversificação de intercâmbios produzem impactos econômicos, políticos e sociais profundos e diferenciados sobre o território.

A proposta da Rede parte do pressuposto de que as universidades que a integram coincidem com a abordagem interdisciplinar construída conjuntamente, sustentada na articulação de conceitos-chave para estudar a integração territorial e o desenvolvimento regional. As representações do território consensuadas por estas instituições incluem multidisciplinarmente abordagens de diferentes disciplinas como: a ecologia que ajuda a perspectiva do desenvolvimento sustentável e manejo do ambiente natural; a geografia para a qual o território é expressão da organização do espaço; a sociologia e a antropologia para as quais o território é construção social; a economia que vê o território como meio de produção e uso de recursos específicos; e a agronomia que considera a atividade agropecuária como produtora de paisagens. Portanto, para os membros da Rede o desenvolvimento territorial é uma construção social, remetendo à ação coletiva, às questões ambientais, à organização produtiva, financeira e comercial, ao ordenamento territorial, de gestão participativa e de fomento da cidadania. 
A produção desse dossiê resulta, portanto, da articulação desta Rede de Desenvolvimento Territorial e Integração Regional, com apoio do ALFA, agregando artigos de representantes formais das instituições que a constituem e de outros autores que compartilham deste debate, resguardando-se a responsabilidade individual de opinião de cada autor.

O artigo de Francisco Entrena Durán apresenta uma proposta metodológica com base nos indicadores para medir o desenvolvimento resultante das transformações nos territórios chamados periurbanos, como espaços de características híbridas entre o rural e a cidade e que se expandem e crescem em muitas cidades do mundo. Do conhecimento da situação econômica e das transformações e tendências neste território, criam-se possibilidades de articular políticas adequadas para regular tais processos.

O dilema político do processo de integração do "território" América Latina e Caribe, na atual encruzilhada histórica, é esmiuçado por Alberto Rocha Valencia. O autor conclui que a região firmou, até agora, apenas um posicionamento econômico débil e político difuso no processo de negociações para a construção da ALCA. Há um complicador nesta encruzilhada histórica que é o dilema político entre integração regional ou integração continental. O autor levanta a hipótese de que a crise do projeto de integração via ALCA possibilita a emergência, por ora em formulações ainda gerais, de projeto de integração regional alternativo.

A discussão sobre o desenvolvimento rural de determinadas regiões e suas articulações externas sob a ótica da abordagem territorial é objeto do texto de Sérgio Schneider, mostrando que as reflexões a respeito buscam compreender as diversidades de escolhas do processo de desenvolvimento em consonância com suas raízes sociais, econômicas e culturais. Schneider desenvolve seu raciocínio em três argumentos centrais: o processo de reestruturação da economia e da sociedade está condicionado pelas relações e mediações entre o local e a reestruturação do capitalismo; o conceito de desenvolvimento rural apóia-se no alargamento do espaço, das ocu- 
pações e do setor; o deslocamento do conceito de região para o de território resgata tanto sua imbricação com a geografia quanto seu uso normativo e operacional para apontar um novo enfoque do desenvolvimento regional. O autor conclui que as articulações e intermediações das dinâmicas locais e territoriais possuem interação com o contexto econômico e societário em que as mudanças sociais transcorrem.

Tomando por referencial teórico a noção de campo e baseando-se em depoimentos de autoridades e dirigentes de sindicatos patronais e de trabalhadores, José Luiz Bica de Mélo analisa os entrelaçamentos entre os conflitos e o imaginário na fronteira brasileiro-uruguaia, decorrente de disputas de terra, do mercado de trabalho e de interpretações das legislações nacionais. Seu texto, escrito antes do recente acordo entre os governos dos dois países, reconhecendo peculiaridades de fronteiras, mostra que a integração das populações de Santana do Livramento (Brasil) e de Rivera (Uruguai) é uma representação discursiva com pouca concretização real.

O geógrafo Aldomar Arnaldo Rückert analisa a estreita interelação entre as políticas territoriais que visam o desenvolvimento endógeno local e a ciência \& tecnologia a partir da experiência gaúcha de criação do Pólo de Modernização Tecnológica da Serra. A vinculação com a ciência é articulada através das universidades regionais, especialmente a de Caxias do Sul. O autor mostra que o sucesso das ações visando implantar políticas de inovações tecnológicas, analisadas nos municípios de Caxias do Sul e de Campestre da Serra, dependem do envolvimento, além do governo, de um conjunto de atores da sociedade civil articulados, no caso, pelo Conselho Regional de Desenvolvimento da Serra.

O dossiê é completado com a análise de Alberto Riella e Alejandra Andrioli, sobre as estratégias políticas, sobretudo as de caráter simbólico, dos grandes pecuaristas uruguaios contemporâneos e suas organizações, para garantir sua hegemonia e seu poder real de mando e impor uma forma de apropriação do território. Os autores pressupõem que as organizações 
sindicais corporativas se envolvem permanentemente em lutas simbólicas como jogo ideológico (visão de mundo) para concretização objetiva de seus interesses em longo prazo. Como conseqüência, seus discursos expressam suas alianças, seus conflitos e seu poder, podendo-se através de sua análise, decifrar sua estratégia simbólica de reprodução social. A hipótese defendida é que a construção social do território se sustenta pela percepção imposta, como poder simbólico concretizado em formas particulares de apropriação e uso da terra como se fosse a única forma possível e legítima de utilização dos recursos naturais. 